\title{
Insulin Resistance in the Third Trimester of Pregnancy Suffering from Gestational Diabetes Mellitus or Impaired Glucose Tolerance
}

\author{
Mohammed Helmy Faris Shalayel, \\ Mohammed Chyad Al-Noaemi ${ }^{2}$ and Salah A.M. Ahmed ${ }^{3}$ \\ ${ }^{1}$ National College for Medical and Technical Studies, \\ ${ }^{2}$ Al-Yarmouk College, Khartoum, \\ ${ }^{3}$ Nile College - Khartoum, \\ Sudan
}

\section{Introduction}

Pregnancy results in a state of insulin resistance (Dahlgren, 2006) that appears to include a decrease in maximum insulin sensitivity or responsivity (Baban et al., 2010). This insulin resistance abates in the postpartum period (Kuhl, 1991). Insulin resistance is defined as the decrease of the biological action of insulin (Catalano, 2010; Robert, 1995), and it mainly presents as hyperinsulinemia (Baban et al., 2010; Robert, 1995) or decreased ability of insulin to regulate glucose utilization (Kim et al., 1996).

The resistance to insulin can be characterized as pre-receptor (insulin antibodies), receptor (decreased number of receptors on the cell surface), or post-receptor (defects in the intracellular insulin signaling pathway). In pregnancy, the decreased insulin sensitivity is best characterized as a post-receptor defect resulting in the decreased ability of insulin to bring about glucose transporter (GLUT4) mobilization from the interior of the cell to the cell surface (Catalano, 2010).

Most pregnant women are able to counteract the insulin resistance state by increasing their insulin secretion. However, when the capacity of insulin secretion is not sufficiently large to meet the insulin resistance, glucose intolerance develops and the women develop gestational diabetes (Kuhl et al., 1985).

Gestational diabetes mellitus (GDM) is defined as a carbohydrate intolerance of varying severity with onset or first recognition during the present pregnancy (Kaaja \& Rönnemaa, 2008; Damm et al., 1994; Summary and recommendation of the second international workshop conference of gestational diabetes, 1985; Shalayel et al., 2010). GDM has onset or discovery of glucose intolerance during pregnancy (Reece et al., 2009), usually in the second or third trimester (Shalayel et al., 2007). GDM carries long-term implications for the subsequent development of type 2 diabetes in the mother and increased risk for obesity and glucose intolerance in the offspring (Barbour et al., 2007). The world health organization defines diabetes in pregnancy as a fasting glucose $\geq 7.9 \mathrm{mmol} / \mathrm{L}$ or a value $>11 \mathrm{mmol} / \mathrm{L} \mathrm{2-}$ hour after a 75g glucose load (Shalayel et al., 2010; Campbell \& Lees, 2000). 
Impaired Glucose Tolerance (IGT) was previously known as chemical diabetes or subclinical diabetes (Shalayel et al., 2007). It may be defined as an intermediate group of individuals whose carbohydrate metabolism does not constitute diabetes but is not entirely normal (Brudenell, 1993). Thus, IGT designed glucose tolerance results intermediate between normal glucose homeostasis and overt diabetes (Kahn et al., 2005; Bilous \& Donnelly, 2010; Burch, 1994). It is diagnosed if fasting glucose $\geq 6$ but $<7.8 \mathrm{~m} \mathrm{~mol} / \mathrm{L}$ or 2-hour glucose $>7.8 \mathrm{~m} \mathrm{~mol} / \mathrm{L}$ and $<11.1 \mathrm{mmol} / \mathrm{L}$ (Shalayel et al., 2010; Hope et al., 1993). About $25 \%$ of patients with IGT eventually become diabetic (Shalayel et al., 2007).

In fact there are significant alterations in glucose metabolism during pregnancy (Catalano, 1994). The carbohydrate tolerance is reduced, especially in the last trimester due to reduced sensitivity to insulin action (Hod \&, Yogev, 2007).

Insulin resistance is defined where a normal or elevated insulin level produces an attenuated biological response classically this refers to impaired sensitivity to insulin mediated glucose disposal (Wilcox, 2005).

The objectives of this study were to stand on the state of insulin resistance that occurs in pregnancy and to assess the possible role of cortisol, human placental lactogen and prolactin in augmentation of such state. The study also showed the effect of some maternal risk factors such as age, parity, previous heavy babies and first-degree family history of diabetes in glucose tolerance impairment in pregnancy.

\section{Subjects and methods}

The study was carried on Sudanese pregnant women in the third trimester $(34.2 \pm 0.63$, $35.97 \pm 0.71$ and $36.53 \pm 0.64$ current week of gestation for the GDM, IGT and control groups respectively).

\subsection{Subjects}

Thirty pregnant women with the GDM,30 pregnant women with IGT and 30 pregnant women with a normal glucose tolerance (control group) chosen from Khartoum teaching hospital, Khartoum north hospital, Soba hospital, Ibrahim Malik hospital, Maternity hospital and Fath-Elrahman Elbasheer referral center. Oral consent was obtained from all the participants involved in the present study.

All subjects overnight fasted before the test. A fasting blood sample was drawn at 6:00 O'clock a.m. then $75 \mathrm{~g}$ oral glucose dissolved in $200 \mathrm{cc}$ water was given for each, waiting for 2 hours and then another blood sample was drawn from each.

\subsection{Parameters analysis}

The concentration of fasting serum c-peptide, serum cortisol, human placental lactogen and prolactin (2-h after 75-g glucose load) were measured with the specific radio-immunoassay. Insulin: the concentrations of serum insulin in the fasting sample $(0 \mathrm{~min})$ and in the 2-hour after $75 \mathrm{~g}$ glucose load sample were measured with the specific immunoradiometric assay (IRMA).

Anti insulin antibodies (AIA): the presence of circulating anti-insulin antibodies is semiquantitatively estimated by determination of the binding of tracer to AIA in the serum fraction. Plasma levels of glucose were assayed with a glucose oxidase kit while serum levels of cholesterol and triacylglycerols (TAGs) were estimated by the specific enzymatic colorimetric methods. 


\subsection{Statistical analysis}

Data were expressed as mean, standard deviation (S.D.), standard error of mean (S.E.), and $95 \%$ confidence interval $(\mathrm{CI})$ for mean. Comparisons were made using one-way analysis of variance (one-way ANOVA) and the significant differences among mean values were indicated by Scheffe test. Data of anti-insulin antibodies (AIA) of different groups of the study were compared by Kruskal-Wallis one-way ANOVA. The differences among the incidence percentages of family history of diabetes and previous heavy babies in the different groups of the study were assessed by calculation of $z$-values and their corresponding p-values. The correlation coefficient $(\mathrm{r})$ is used to measure the closeness of the linear relationship between age and $2 \mathrm{~h}$-plasma glucose and between parity and $2 \mathrm{~h}$-plasma glucose. Calculations were performed using Statistical Packages for Social Sciences (SPSS) program.

\section{Results}

The GDM and the IGT pregnant women were found to be significantly older than the control women [32.8 \pm 0.93 year (mean \pm S.E.) and $31.1 \pm 1.1$ vs. $23.9 \pm 0.82$ respectively, $p<0.0001]$. Incidence of previous heavy babies ( $\geq 4.5 \mathrm{~kg}$ at birth) of the IGT group was significantly higher than that of the control group $(33.3 \%$ vs $6.7 \%, z=2.25$ and $p<0.05)$. Also, incidence of previous heavy babies of the GDM group was significantly higher than that of the control group ( $46.7 \%$ vs $6.7 \%, z=3.2$ and $\mathrm{p}<0.01)$.

Percentage of first degree family history of diabetes was significantly higher in the IGT group when compared with that of the control group $(36.7 \%$ vs $10 \%, z=2.1$ and $p<0.05)$. Much higher significant difference was shown between the GDM group and the control group $(53.3 \%$ vs $10 \%, z=3.3$ and $p<0.001)$.

\subsection{Plasma levels of glucose}

The GDM women were found to have higher mean levels of plasma glucose when compared with the IGT and the control pregnant women as shown in table 1 and table 2 $(\mathrm{p}<0.0001)$.

\begin{tabular}{|l|l|l|l|l|}
\hline & Mean & S.D. & S.E. & $95 \%$ CI \\
\hline GDM & $7.59^{* *}$ & 1.85 & 0.34 & $6.9-8.28$ \\
\hline IGT & $5.9^{*}$ & 0.45 & 0.082 & $5.73-6.07$ \\
\hline Control & 2.91 & 0.43 & 0.079 & $2.75-3.07$ \\
\hline
\end{tabular}

* Significant ** Highly significant

Table 1. Fasting plasma glucose levels $(0 \mathrm{~min})$ in the three studied groups ( $\mathrm{mmol} / \mathrm{L})$

\begin{tabular}{|l|l|l|l|l|}
\hline & Mean & S.D. & S.E. & 95\% CI \\
\hline GDM & $12.35^{* *}$ & 3.11 & 0.57 & $11.19-13.51$ \\
\hline IGT & $7.98^{*}$ & 0.69 & 0.13 & $7.72-8.23$ \\
\hline Control & 4.35 & 0.65 & 0.12 & $4.11-4.6$ \\
\hline
\end{tabular}

* Significant ${ }^{* *}$ Highly significant

Table 2. 2h-plasma glucose levels (120 $\mathrm{min})$ in the three studied groups (mmol/l) 


\subsection{Serum cholesterol and triacylglycerols results}

It was found that the mean levels of serum cholesterol of the IGT group and that of the GDM group were significantly higher than that of the control group $[252.5 \pm 13.17 \mathrm{mg} / \mathrm{dl}$ (mean \pm S.E.), 239.07 \pm 14.82 vs $195.73 \pm 8.47$ respectively, $\mathrm{F}=6.22$ and $\mathrm{p}<0.003]$.

Also, it was found that the mean levels of serum triacylglycerols of the GDM group and that of the IGT group were significant higher than that of the control group $[278.47 \pm 15.90 \mathrm{mg} / \mathrm{dl}$ (mean \pm S.E.), $259.37 \pm 11.6$ vs $188.63 \pm 8.92$ respectively, $F=17.81$ and $p<0.0001]$.

But, there was no significant difference between the mean levels of TAGs of the GDM group and that of the IGT group although the serum TAGs levels were greater in the GDM group.

\subsection{Serum c-peptide results}

Fasting c-peptides mean of the IGT group was not significantly higher than that of the GDM and control groups $[0.34 \pm 0.04 \mathrm{p} \mathrm{mol} / 1$ (mean \pm S.E.) vs $0.26 \pm 0.03$ and $0.28 \pm 0.04$ respectively, $\mathrm{p}>0.05]$.

\subsection{Serum levels of cortisol}

There was a highly significant difference $(p<0.0003)$ between serum level of cortisol of the GDM group and the IGT group from one hand and between the GDM group and the control group from other hand (table 3 ).

\begin{tabular}{|l|l|l|l|l|}
\hline & Mean & S.D. & S.E. & $95 \%$ CI \\
\hline GDM & $937.2^{* *}$ & 434.8 & 79.38 & $774.9-1099.6$ \\
\hline IGT & $794.2^{*}$ & 331.5 & 60.52 & $670.4-918$ \\
\hline Control & 597.3 & 169.4 & 30.93 & $534-660.5$ \\
\hline
\end{tabular}

* Significant ${ }^{* *}$ Highly significant

Table 3. Serum cortisol (nmol/l) values of the three studied group

\subsection{Serum levels of insulin}

There was no significant difference among the mean fasting serum insulin levels of the studied groups [12.29 $\pm 0.83 \mathrm{MIU} / \mathrm{ml}$ (mean \pm S.E.), $14.93 \pm 2.17$ and $2.39 \pm 2.25$ for the GDM, IGT and control groups respectively, $\mathrm{p}>0.05]$.

The men level of $2 \mathrm{~h}$-serum insulin of the IGT group was significantly higher than that of the GDM group ( $68 \pm 6.71$ vs $36.5 \pm 3.06, p<0.002)$ while, it was not significantly higher than that of the control group ( $68 \pm 6.71$ vs $54.88 \pm 8.15)$.

\subsection{Serum anti-insulin antibodies (AIA) results}

The results of AIA binding percentage to the tracer (table 4) showed significant difference among the three studied groups $\left[\mathrm{X}^{2}(\mathrm{df}=2)=7.34, \mathrm{p}<0.025\right]$.

\begin{tabular}{|l|l|l|l|l|l|}
\hline & Mean & S.D. & S.E. & $\begin{array}{l}95 \% \text { CI for } \\
\text { mean }\end{array}$ & Mean rank \\
\hline GDM & $25.11^{* *}$ & 31.01 & 5.66 & $13.53-36.69$ & 54.25 \\
\hline IGT & $7.18^{*}$ & 2.47 & 0.45 & $6.25-8.10$ & 46.23 \\
\hline Control & 6.04 & 1.50 & 0.27 & $5.48-6.60$ & 36.02 \\
\hline
\end{tabular}

* Significant ** Highly significant

Table 4. Percent bound results of serum AIA 


\subsection{Serum hPL results}

Although the mean HPL levels of the IGT group and that of the GDM group were higher than that of the control group, there were no significant differences among them $[7.15 \pm 0.49 \mathrm{Mg} / \mathrm{ml}$ (mean \pm S.E.), $6.85+0.58$ and $5.73 \pm 0.24, \mathrm{p}>0.05]$.

\subsection{Serum prolactin results}

Although the control group recorded the highest levels of serum prolactin and the GDM recorded the lowest results, there were no significant differences among the studied groups $[123.6 \pm 9.61 \mathrm{ng} / \mathrm{dl}$ (mean \pm S.E.), $145 \pm 15$ and 150.2 \pm 9.7 for the GDM, IGT and control groups respectively, $\mathrm{p}>0.05]$.

\section{Discussion}

There is an increased frequency of gestational diabetes in oriental women and those from the Indian subcontinent and the Middle East (Stewart \& Taylor, 1994). Pregnancy and diabetes mellitus aggravate each other (Potemkin, 1989). Hormonal changes occur in pregnancy, which profoundly affect carbohydrate metabolism. The levels of estrogen, progesterone, human placental lactogen, free cortisol and prolactin rise progressively as pregnancy advances. Of these a number, notably human placental lactogen and cortisol are insulin antagonists. So, insulin resistance develops in the mother as the pregnancy progresses, and it is most marked in the last trimester. This leads to deterioration in glucose tolerance (Brudenell, 1993). This explains why IGT and GDM were only discovered in the third trimester of gestation.

The results showed that many maternal risk factors affect the incidence of abnormal glucose tolerance (IGT \& GDM) in Sudanese pregnant women.

Maternal age is an established risk factor for gestational diabetes mellitus (GDM), but there is no consensus on the age above which there is significantly increased risk of GDM (American Diabetes Association, 2004). The finding that the IGT and the GDM groups were significantly older than those with normal glucose tolerance (control) group, agrees with many previous studies that approved the direct relation between advanced maternal age $(<35)$ and greater risk for incidence of GDM (Solomon et al., 1997; Cianni et al., 2003). Moreover, the presence of a linear relationship between the age and the $2 \mathrm{~h}$-plasma glucose ensure that there is an age related deterioration of glucose tolerance and makes the age a very important maternal risk factor to affect glucose intolerance incidence.

The association between parity and diabetes seems consistent in different studies. Women with highest parity are frequently older and heavier. Therefore, no study that evaluates parity could ignore a proper age adjustment (Dode \& dos Santos, 2009). Multiparity has been associated with GDM in some studies but not in other ones (Seghieri et al., 2005; BenHaroush et al., 2004).

Kumari et al. (2002) found that grand multiparous women with parity $\geq 10$ had greater gestational diabetes mellitus incidence.

Significant higher mean parity of the IGT and the GDM groups when compared with the mean parity of the control (normal glucose tolerance) group as well as the existence of a linear relationship between parity and the $2 \mathrm{~h}$-plasma glucose, make the parity a very important maternal risk factor in impairment of glucose tolerance. This may be explained in terms of the diabetogenicity of the pregnancy, which is related to a pronounced peripheral 
resistance to insulin (Kuhl, 1991). Parity reflects the duration of exposure to the insulin resistance (Peters et al., 1995). Thus, one can conclude that higher parity may lead to accumulation of the diabetogenic effect of pregnancy. Consequently, much more glucose impairment occurs.

Genetic factors play a part in the development of diabetes although the exact mode of inheritance is not established (Brudenell, 1993). Recent evidence suggests that the gestational diabetes has a strong genetic component and is usually NIDDM. Both GDM and NIDDM are characterized by insulin deficiency and by insulin resistance (Dornhorst et al., 1990). This evidence agrees with that of Csorba and Edwards (1995) who showed that the development of both type II and GDM is probably governed by a complex and variable interaction of genes and environments. Moreover, they suggest that both beta cell dysfunction and insulin resistance is operative in the manifestation of these disorders. This may explain why the incidence of first degree family history of diabetes was significantly higher in the GDM and in the IGT groups when compared with that of the control group. Therefore, family history of diabetes is a very important maternal risk factor from the obstetrician's point of view (Brudenell, 1993).

The result that the GDM and the IGT groups have incidence of previous heavy babies significantly higher than that of control group, make previous delivery of a large baby to be a very important maternal risk factor since a tendency to bear heavy babies may precede the development of clinical diabetes by many years (Brudenell, 1993).

Changes in lipid metabolism occur during pregnancy. Plasma levels of triglycerides, cholesterol and free fatty acids rise, and there is a greater tendency to ketosis (Campbell \& Lees, 2000). Some studies showed that total triglycerides increase with gestational time in pre-gestational diabetic women, GDM women and healthy control women (Montelongo et al., 1992).

Every aspect of lipid metabolism is affected by pregnancy. The plasma level of free fatty acids falls from early to mid-pregnancy and thereafter shows a significant rise. The same is true for the plasma level of glycerol. This is in keeping with the accumulation of body fat that occurs during the anabolic phase of pregnancy (first two trimesters). In the catabolic phase of pregnancy (last trimester), raised free fatty acids and glycerol levels are available as fuel to the maternal tissues to offset the increasing diversion to the rapidly growing fetus of glucose and amino acids. As with free fatty, glycerol and triglycerides, plasma levels of cholesterol and phospholipids are increased in pregnancy (Brudenell, 1993) taking in account that plasma triglycerides may be a physiological contributor to infant birth weight (Knopp et al., 1992). Thus, one can expect more increase of these lipid substances when the glucose tolerance deteriorates in pregnancy. Therefore, the mean level of serum cholesterol and triglycerides were significantly higher in the GDM and in the IGT groups when compared with the control (normal glucose tolerance) group.

The changes in lipid metabolism are mediated by hormonal changes and fit into the general pattern of an increase in storage of glycogen and fat in most maternal tissues during the metabolic first two trimesters of pregnancy, followed by the mobilization of fuel for the benefit of both mother and fetus in catabolic third trimester (Brudenell, 1993).

Boden (1996) demonstrated that in early pregnancy, insulin secretion in response to glucose is increased, peripheral insulin sensitivity is normal or increased and glucose tolerance is normal or slightly enhanced. In addition, there is maternal fat accumulation. During late pregnancy, there is increased fetal growth and increased fetal demand for nutrients. 
Maternal responses to these demands consist of an accelerated switch from carbohydrate to fat utilization that is facilitated by peripheral insulin resistance and by high blood levels of lipolytic hormones. In patients with GDM, insulin resistance is either comparable or greater than in non-diabetic pregnancy whereas insulin secretion appears to be compromised.

Changes in hepatic and adipose metabolism alter circulating concentrations of triacylglycerols, fatty acids, cholesterol, and phospholipids. After an initial decrease in the first $8 \mathrm{wk}$ of pregnancy, there is a steady increase in triacylglycerols, fatty acids, cholesterol, lipoproteins, and phospholipids (Butte, 2000). There is a two- to threefold increase in basal triglyceride and cholesterol concentrations with advancing gestation. The increases are more pronounced in the GDM as compared with the normal glucose tolerant pregnant woman (Catalano, 2010). The higher concentration of estrogen and insulin resistance are thought to be responsible for the hypertriglyceridemia of pregnancy (Butte, 2000).

Thus, it is concluded that in the third trimester of pregnancy, there is a competition between mother and her fetus on glucose uptake. This competition will be directed towards the benefit of the fetus. For this reason, the pregnant women do switch to other energy source rather than glucose such as fat to overcome the state of insulin resistance.

The syndrome of insulin resistance is a group of clinically diverse disorders (Catalano, 2010; Flier, 1992). Pregnancy induces complex changes in energy metabolism, manifested clinically by insulin resistance (Bedalov \& Balasubramanyam, 1997). Glucose tolerance deteriorates in all pregnant women, but only in $2-3 \%$ of all pregnancies is the deterioration sufficiently large to fulfill the diagnostic criteria for gestational diabetes1. Many previous studies demonstrated that pregnancy result in a state of insulin resistance and women with gestational-onset diabetes appear to have a greater degree of insulin resistance (Ryan et al., 1985).

Why pregnancy is capable of inducing the temporary diabetic state is still partly unknown, although many other studies tried to put general points to explain this state.

Bergstrom et al. (1990) revealed that an increased fasting c-peptide reflects insulin resistance. In fact, insulin and c-peptide are secreted in equimolar amount. However, because of its longer half-life, the plasma concentration of c-peptide is higher than that of insulin. Within limits, c-peptides levels can serve as valuable index to insulin secretion. Thus, low c-peptide levels are to be expected when insulin secretion is diminished whereas elevated c-peptides may result from increased beta-cells activity.

Regarding our results, the serum fasting c-peptide mean level was the highest in the IGT groups $(0.337 \pm 0.038 \mathrm{Pmol} / \mathrm{L})$ when compared with the GDM group $(0.262 \pm 0.025)$ and the control group $(0.284 \pm 0.041)$ although the differences were not significant $(\mathrm{P}>0.05)$. This gives prediction to the higher insulin resistance in the IGT group when compared with the control group.

Most pregnant women are able to counteract the insulin resistance in pregnancy by increasing their insulin secretion. This also explains the highest mean levels of insulin in the IGT group when compared with the control group.

Although the insulin levels, (fasting and $2 \mathrm{~h}$-insulin) were lower in the control group than that of the IGT group, the glucose tolerance kept normal. This may support the suggestion that during normal pregnancy, the Staub-Traugott effect i.e., improved glucose disposal after successive glucose load administrations occurs and appears to be caused by mechanisms other than enhanced insulin secretion with successive glucose loads (Lewis et al., 1993).

However, when the capacity of insulin secretion is not sufficiently large to meet the resistance, glucose intolerance develops and the women develop gestational diabetes 
(Shalayel et al., 2010; Buchanan \& Xiang, 2005). This may be due to the presence of high levels of insulin antagonistic hormones as hPL and cortisol (Carr \& Gabbe, 1998) as well as high level of circulating anti-insulin antibodies which may make the pregnant women secrete more insulin to overcome the insulin resistance and eventually may lead to exhaustion of beta-cells of the pancreas. This explain the lowest mean levels of fasting cpeptide, fasting serum insulin and $2 \mathrm{~h}$-serum insulin in the GDM group when compared with the IGT and the control groups.

Damm et al. (1995) demonstrated that women who develop GDM have a relative insulin secretion deficiency, the severity of which is predictive for later development of diabetes. Furthermore, their relatively reduced beta-cells functions may be a significant pathogenic factor in relation to the high incidence of subsequent diabetes in women with GDM. This agrees with Paulus et al. (1995) who showed that the diagnoses of gestational diabetes mellitus are at a greater risk for developing diabetes in later life.

Homko et al (2001) reported that patients with GDM during late pregnancy not only had severe deficiencies in insulin secretion rate (ISR) and were more insulin resistant than controls. In addition, the women with GDM had a major B-cell defect that made it impossible for them to compensate for their increased level of insulin resistance, which occurred during late pregnancy.

Our study also showed that the cortisol increases progressively as pregnancy advances and the mean cortisol level was significantly the highest in the GDM group when compared with the IGT and the control groups while its level was the lowest in the control group in the third trimester. This ensures the possibility role of cortisol as an insulin antagonist in the deterioration of the glucose tolerance in pregnancy.

Cortisol is bound in the circulation to alpha-globulin called transcortin or corticosteroidbinding globulin (CBG). The bound cortisol functions as circulating reservoir of hormone that keeps a supply of free cortisol available to the tissues. At normal levels of total plasma cortisol $(13.5 \mu \mathrm{g} / \mathrm{dL})$, there is very little free cortisol in plasma, but the binding sites on CBG become saturated when the total plasma cortisol exceeds $20 \mu \mathrm{g} / \mathrm{dL}$. CBG is synthesized in the liver, and its production is increased by estrogen and its level is elevated during pregnancy. When the CBG level rises, more cortisol is bound, and initially there is a drop in the free cortisol level which stimulates adrenocorticotrophic hormone (ACTH) secretion. Therefore, more cortisol is secreted until a new equilibrium is reached at which the bound cortisol is elevated but the free cortisol is normal. Changes in the opposite direction occur when the CBG level falls. This explains why pregnant women have higher total plasma levels of cortisol without symptoms of glucocorticoids excess (Barrett et al., 2010). Cortisol is nearly totally $(90 \%)$ bound to CBG up to concentrations of $25 \mu \mathrm{g} / \mathrm{dL}$. But, when cortisol concentrations rise above this level, as occurred in the IGT group (serum cortisol mean level $=28.57 \mu \mathrm{g} / \mathrm{dL}$ ) and in the GDM group (serum cortisol mean level $=33.71 \mu \mathrm{g} / \mathrm{dL}$ ), the binding capacity of CBG is exceeded and the proportion of unbound, free, cortisol rises greatly (Burch, 1994). This free cortisol increases glucose tolerance deterioration therefore confirms the dominating role of cortisol as a regulator of stress dependent insulin resistance (Lehrke et al., 2008).

Human placental lactogen (hPL) is a single protein of 191 amino acids, which is encoded by two genes hPL/CS-A and hPL/CS-B, which are identical except for one minor difference in the single sequence coding region. The $\mathrm{hPL} / \mathrm{CS}$ genes are clustered together with the pituitary growth hormone gene (hGH-N) and a variant $\mathrm{GH}$ gene, $\mathrm{hGH}-\mathrm{V}$, on the long arm of 
chromosome (Davis, 1990). Human PL has only a limited homology with prolactin, but a very high homology with the growth hormone mRNA coding sequence, although in other species there is a more homology with prolactin than growth hormone. The hormone is synthesized in the syncytiotrophoblastic villous epithelium of the placenta and it is secreted into maternal blood (Davis, 1990; Strauss \& Barbieri, 2009). Maternal serum hPL levels rise progressively from the first trimester through till term (Strauss \& Barbieri, 2009) and this agrees with our results of serum hPL in the control group. Although, there were no significant differences among hPL mean level of the IGT and the GDM groups were higher than that of the control group. This non-significant slight increase in the IGT and the GDM groups may share in increasing insulin resistance in these groups when compared with control group.

Some authors reported that pronounced fetal macrosomia may occur even with adequate maternal blood glucose control. The severe fetal hyperinsulinemia in this case may be imputed to some factor other than excessive glucose load, possibly hPL, which induces proliferation and enhanced function of pancreatic B-cells. In concert with this hypothesis, maternal serum hPL concentrations measured in the third trimester are higher in diabetic pregnancies complicated by fetal macrosomia (Persson et al., 1995; Reis et al., 2002).

The regulation of hPL secretion is not fully understood. Progesterone exerts stimulatory effects in early gestation, but not in late gestation. Finally the hPL/CS gene contains a binding site for the glucocorticoids receptor, suggesting a potential modulatory role for corticosteroids, and also has binding sites for a pituitary protein factor that is thought to regulate both prolactin and growth hormone gene expression (Davis, 1990). Furthermore, the very high levels of circulating estrogen that occur during pregnancy result in a parallel increase in the circulating levels of prolactin (Schlechte, 2007). This may explain the interconnection between hPL and prolactin since, it seems that prolactin, growth hormone and placental lactogen hormone are phylogenetically ancient hormones which in vertebrates have evolved from common ancestral molecules. These hormones share common effects in growth stimulation and lactation. Hypersomatotropism is associated with disturbance of glucose tolerance and insulin resistance. Hyperprolactinaemia, like hypersomatotropism, is associated with decreased insulin sensitivity (Foss et al., 1995).

The present study (on control group) demonstrated that prolactin increases progressively from the first trimester through till third trimester. Moreover, our study revealed that there were no significant differences among the levels of serum prolactin in GDM, IGT, and control groups. This agrees with what has been mentioned by Grigorakiz et al. (2000). Consequently, there is no evidence that prolactin may be directly incorporated with the pathogenesis of glucose intolerance in pregnancy. This may agree with the study of Milasinović et al. (1997) who reported that there is no evidence of the functional connection between prolactin and glucose metabolism.

Prolactin is found in large amounts in the amniotic fluid of humans and other primates, and it is now clearly established that the source of this prolactin is the placenta rather than the maternal or fetal pituitary. The endometrial lining of the uterus is greatly modified during pregnancy to form the decidua. This decidual tissue has been confirmed as the site of placental prolactin production by a number of different groups and the mature peptide hormone is immunologically indistinguishable from pituitary prolactin. Immunocytochemical studies have shown that the hormone is predominantly located in the parietal decidual cells and only very rarely in the chorionic cytotrophoblast. Amniotic fluid prolactin levels are very low in ectopic tubal pregnancy, confirming the role of the decidualized endometrium (Davis, 1990). 
Amniotic fluid prolactin levels rise progressively after the $14^{\text {th }}$ week human gestation and decline somewhat during the $3^{\text {rd }}$ trimester. Prolactin secretion by the deciduas appears to be regulated quite differently from that in the pituitary gland. The first striking difference in regulation is that dopamine and dopamine agonists' drugs have no inhibitory effect on decidual prolactin secretion or amniotic fluid prolactin levels. Estrogen exerts a strong stimulation on pituitary lactotrophs but appears at most to have only small effects on decidual prolactin production (Davis, 1990).

The very high levels of circulating estrogen during pregnancy result in a parallel increase in the circulating levels of prolactin in pregnancy. The prolactin increase is to prepare the breasts for lactation. Prolactin levels begin to rise at 5-8 weeks of gestation and parallel the increase in the size and number of lactotrophs (Schlechte, 2007; Corenblum, 2008).

Progesterone appears to stimulate decidual prolactin secretion although it has little or no effect on decidual cells obtained in early pregnancy. Insulin stimulates both acute secretion and de novo synthesis of decidual prolactin (Davis, 1990). This may explain why prolactin mean level was the lowest in the GDM group as the level of insulin, which stimulates prolactin secretion, is the lowest when compared with the other groups (IGT and the control groups).

\section{Conclusion}

Now, it is clear that pregnancy is diabetogenic and characterized by increased insulin resistance which may be explained in term of reduced insulin secretion, reduced tissue sensitivity to insulin and increased secretion of hormones with an anti-insulin effect such as human placental lactogen, free cortisol and prolactin. All these characteristics with the incorporation of some maternal risk factors such as age, parity, previous heavy babies and family history of diabetes may lead to the impairment of glucose tolerance in some pregnant women. Most pregnant women are able to counteract the insulin resistance in pregnancy by increasing their insulin secretion or by switching to other energy source rather than glucose such as fat particularly in the third trimester to preserve glucose to the fetus. However, when the capacity of insulin secretion is not sufficiently large to meet the resistance, glucose intolerance develops and women develop gestational diabetes.

\section{Abbreviation}

GDM, gestational diabetes mellitus; IGT, impaired glucose tolerance; hPL, human placental lactogen; TAGs, triacylglycerol; NIDDM, non-insulin dependent diabetes mellitus; CBG, corticosteroid-binding globulin; ACTH, adrenocorticotrophic hormone.

\section{References}

American Diabetes Association. (2004). Gestational diabetes mellitus. Diabetes Care, 27 (Suppl. 1):S88-S90.

Baban RS, Kasar KAK, Al-Karawi IN. (2010). Fasting glucose to leptin ratio as a new diagnostic marker in patients with diabetes mellitus. OMJ, 25(4):269-275. 
Barbour LA, Carrie E. McCurdy, Teri L. Hernandez, John P. Kirwanet et al. (2007). Cellular Mechanisms for Insulin Resistance in Normal Pregnancy and Gestational Diabetes. Diabetes Care, 30 (2): S112-S119.

Barrett K, Brooks H, Boitano S, Barman S. (2010). The adrenal medulla and adrenal cortex, In: Ganong's Review of Medical Physiology (23rd edition), pp. 346-347, The Mc Grow Hill Companies, ISBN: 978-0-07-160567-0, USA.

Bedalov A. and Balasubramanyam A. (1997). Glucocorticoid- induced ketoacidosis in gestational diabetes: Sequela of the acute treatment of preterm labor. A case report. Diabetic Care, 20(6): 922-924.

Ben-Haroush, A., Yogev, Y., Hod, M. (2004). Epidemiology of gestational diabetes mellitus and its association with type 2 diabetes. Diabetic Medicine, 21: 103-113.

Bergstrom R.W., Newell-Morris L.L., Leonetti D. L., et al. (1990). Association of elevated fasting C-peptide level and increased intra-abdominal fat distribution with development of NIDDM in Japanese- American men. Diabetes, 39 (1): 104-111.

Bilous R, Donnelly R. (2010). Hand book of Diabetes (4th edition), Wiley-Blackwell, ISBN: 9781405184090, UK.

Boden G. (1992). Fuel metabolism in pregnancy and in gestational diabetes mellitus. Obstetgynecol. Clin. North Am., 23 (1): 1-10.

Brudenell M. (1993) Diabetic pregnancy. In: Obstetrics (2nd edition), Turnbull S. A., Chamberlain G. (eds). pp. 585-602, Churchill Livingstone, Edinburgh, London, Melbourne and Newyork.

Buchanan TA, Xiang AH. (2005). Gestational diabetes mellitus. J Clin Invest, 115(3): 485-491.

Burch W. M. (1994). Endocrinology (3rd edition), Mass Publishing Co., ISBN: 977-269-018-7, Egypt.

Butte N.F. (2000). Carbohydrate and lipid metabolism in pregnancy: normal compared with gestational diabetes mellitus. American Journal of Clinical Nutrition, 71(5): 1256S$1261 S$.

Campbell S. and Lees C. (Eds). (2000). Obstetrics by Ten Teachers, 17th edition. Arnold, ISBN 0 34074082 5, London.

Carr DB, Gabbe S. (1998). Gestational Diabetes: Detection, Management, and Implications. Clin Diabetes, 16(1): 4-11.

Catalano P. M. (1994). Carbohydrate metabolism and gestational diabetes. Clin. Obstet. Gynecol, 37(1): 25-38.

Catalano PM. Obesity, insulin resistance, and pregnancy outcome. Reproduction (2010) 140 365-371.

Cianni GD, Volpe L, Lencioni C, et al. (2003). Prevalence and risk factors for gestational diabetes assessed by universal screening. Diabetes research and clinical practice, 62(2): 131-137.

Corenblum B. (2008). Pituitary Disease and Pregnancy, In: eMedicine from WebMD. Article Last Updated: Jun 25, 2008. http://emedicine.medscape.com/article/127650overview.

Csorba T. R. and Edwards A. L. (1995). The genetic and pathophysiology of type II and gestational diabetes. Crit. Rev. Clin. Lab. Sci., 32 (5-6): 509-550. 
Dahlgren J. (2006). Pregnancy and insulin resistance. Metabolic Syndrome and Related Disorders, 4(2): 149-152.

Damm P., Kuhl C., Buchard K., et al. (1994). Prevalence and predictive value of islet cell antibodies and insulin autoantibodies in women with gestational diabetes. Diabetic Medicine, 11: 558-563.

Damm P., Kuhl C., Hornnes P. and Molsted-Pedersen L. (1995). A longitudinal study of plasma insulin and glucagon in women with previous gestational diabetes. Diabetes care, 18 (5): 654-665.

Davis JRE. (1990). Prolactin and related peptides in pregnancy. Baillière's Clinical Endocrinology and Metabolism, 4(2): 273-290.

Dode MAS, dos Santos I S. (2009). Non classical risk factors for gestational diabetes mellitus: a systematic review of the literature. Cad. Saúde Pública, 25 (supl.3) Rio de Janeiro.

Dornhorst A., Nicholls J. S. D. and Johnston D.G. (1990). Diabetes and diet in pregnancy. Bailliere's Clinical Endocrinology and Metabolism, 4 (2): 291-311.

Flier J. S. (1992). Lilly lecture: Syndromes of insulin resistance- From patient to gene and back again. Diabetes, 41: 1207-1219.

Foss M. C., Paula F. J. A., Paccola G. M. G. F. and Piccinato C. E. (1995). Peripheral glucose metabolism in human prolactinaemia. Clinical Endocrinology, 43 (6): 721 -726.

Grigorakis SI, Alevizaki M, Beis C, et al. (2000). Hormonal parameters in gestational diabetes mellitus during the third trimester: High glucagon levels. Gynecological and Obstetric investigation, 49: 106 - 109.

Hod M., Yogev Y. (2007). Goals of Metabolic Management of Gestational Diabetes- Is it all about the sugar? Diabetes Care, 30(Supplement 2): S180-S187.

Homko C, Sivan E, Chen X, et al. (2001). Insulin Secretion during and after Pregnancy in Patients with Gestational Diabetes Mellitus. The Journal of Clinical Endocrinology $\mathcal{E}$ Metabolism, 86(2): 568-573.

Hope R. A., Longmore J. M., Hodgetts T. J. \& Ramrakha P. S. (1993). Oxford handbook of clinical medicine (3rd edition), Oxford University Press, ISBN-13: 9780192621153, USA.

Kaaja R, Rönnemaa T. (2008). Gestational Diabetes: Pathogenesis and Consequences to Mother and Offspring. Rev Diabet Stud, 5(4):194-202.

Kahn CR. Weir GC. King GL. et al. (2005). Joslin's Diabetes Mellitus (14th edition), Lippincott Williams \& Wilkins. ISBN: 0-7817-2796-0. USA. Pp 332-336.

Kim J. K., Wi J. K. and Young J. H. (1996) Plasma free fatty acids decrease insulin-stimulated skeletal muscle glucose uptake by suppressing glycolysis in conscious rats. Diabetes, 45: 446-453.

Knopp R. H., Magee M. S., Walden C. E., et al. (1992). Prediction of infant birth weight by GDM screening test-Immportance of plasma triglycerides. Diabetes Care, 15(11): 1605-1613.

Kuhl C. (1991). Aetiology of gestational diabetes. Bailliere's Clinical Obstetrics and Gynaecology, 5(2): 279-292.

Kuhl C., Hornnes P. J. and Andersen O. (1985). Etiology and pathophysiology of gestational diabetes mellitus. Diabetes, 34 (suppl.2): 66-70.

Kumari AS, Badrinath P. (2002). Extreme grandmultiparity: is it an obstetric risk factor? Eur J Obstet Gynecol Reprod Biol., 101:22-5. 
Lehrke M, BroedlUC, Biller-Friedmann IM, et al. (2008). Serum concentrations of cortisol, interleukin 6, leptin and adiponectin predict stress induced insulin resistance in acute inflammatory reactions. Critical Care, 12 (6): R157.

Lewis G. F., McNally C., Blackman J. D., et al. (1993). Prior feeding alters the response to the 50 -g glucose challenge test in pregnancy- The Staub-Traugott effect revisited. Diabetes Care, 16 (12): 1551-1556.

Milasinović L, Djurdjević J, Dokmanović-Djordjević M, et al. (1997). Prolactin levels in pregnant women with glucose intolerance at full-term delivery. Med Pregl, 50:269-73.

Montelongo A. Lasunciaon M. A., Pallardo L. F. and Herrera E. (1992). Longitudinal study of plasma lipoproteins and hormones during pregnancy in normal and diabetic women. Diabetes, 41 (12): 1651-1659.

Paulus W. E., Stoz F., Bugan S. and Kreienberg R. (1995). Disorder of glucose metabolism and insulin resistance after gestational diabetes. Zentralblatt fur Gynakologie, 117 (8): 417-422.

Persson B, Hanson U, Marcus C. (1995). Gestational diabetes mellitus and paradoxical fetal macrosomia - a case report. Early Hum Dev., 41:203-213.

Peters R., Kjos S., Xiang A. and Buchanan T. (1995). Effect of a second pregnancy on the risk of non-insulin-dependent diabetes in women with recent gestational diabetes. Diabetes, Abstracts book. 44(suppl.1): 14A (abstract no. 45).

Potemkin V. (1989). Diseases of the Ilet Apparatus of the Pancreas, In: Endocrinology (2nd edition), pp. (185-243), Mir Publishers, ISBN: 5-03-000754-7, Moscow.

Reece EA, Leguizamon G, Wiznitzer A. (2009). Gestational diabetes: the need for a common ground. Lancet, 373(9677): 1789-97. [abstract]

Reis FM, D'Antona D and Petraglia F. (2002). Predictive Value of Hormone Measurements in Maternal and Fetal Complications of Pregnancy. Endocrine Reviews, 23 (2): 230-257.

Robert J.J. (1995). Methods de mesure de la resistance a l'insulin-clamp hyperinsulinemique euglycemique. La press Medicale, 24 (15): 730-734.

Ryan E. A., O'sullivan M. J. and Skyler J. S. (1985). Insulin action during pregnancy- Studies with the euglycemic clamp technique. Diabetes, 34: 380-389.

Schlechte JA. (2007). Long-term management of prolactinomas. J Clin Endocrinol Metab, 92(8):2861-5.

Seghieri, G., De Bellis, A., Anichini, R., et al. (2005). Does parity increase insulin resistance during pregnancy? Diabetic Medicine, 22: 1574-1580.

Shalayel MH, Ahmed SA, Khattab AH, Satti GM. (2007). Prevalence of gestational diabetes mellitus and impaired glucose tolerance in pregnant Sudanese women in the third trimester. Sudan Medical Monitor, 2(2): 59-61. ISSN: 1858-5000.

Shalayel MH, Elrobh MS, Idris SA, Mohammed MS, Ahmed SA. (2010). Prolactin and insulin estimates in pregnancy with glucose intolerance. Pak J Med Sci., 26(1):102106.

Solomon GC, Willet WC, Carey VJ. et al. (1997). A Prospective Study of Pregravid Determinants of Gestational Diabetes Mellitus. JAMA, 278(13):1078-1083.

Stewart M. and Taylor R. (1994). Gestational diabetes mellitus. Prof. Care-Mother-child, 4(5): 136-138. 
Strauss JF \& Barbieri RL. (2009). The endocrinology of human pregnancy and fetoplacental neuroendocrine development, In: Yen and Jaffe's Reproductive Endocrinology Physiology, pathophysiology and clinical management (6th edition), Strauss JF \& Barbieri RL, pp. 256, Saunders Elsevier, ISBN: 978-1-4160-4907-4, Philadelphia.

Summary and recommendation of the second international workshop conference of gestational diabetes. (1985). Diabetes, 34 (suppl.2): 123-126.

Wilcox G. (2005). Insulin and Insulin Resistance. Clin Biochem Rev, 26(2): 19-39. 


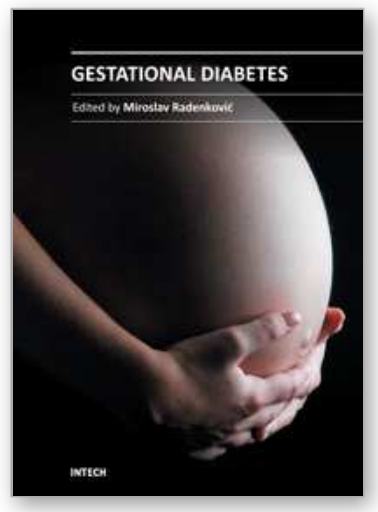

\author{
Gestational Diabetes \\ Edited by Prof. Miroslav Radenkovic
}

ISBN 978-953-307-581-5

Hard cover, 382 pages

Publisher InTech

Published online 02, November, 2011

Published in print edition November, 2011

Gestational diabetes mellitus is defined as hyperglycemia with onset or first recognition during pregnancy. The incidence of gestational diabetes is still increasing and this pathological condition has strong association with adverse pregnancy outcomes. Since gestational diabetes can have long-term pathological consequences for both mother and the child, it is important that it is promptly recognized and adequately managed. Treatment of gestational diabetes is aimed to maintain euglycemia and it should involve regular glucose monitoring, dietary modifications, life style changes, appropriate physical activity, and when necessary, pharmacotherapy.

Adequate glycemic control throughout the pregnancy can notably reduce the occurrence of specific adverse perinatal and maternal outcomes. In a long-term prospect, in order to prevent development of diabetes later in life, as well to avoid associated complications, an adequate education on lifestyle modifications should start in pregnancy and continue postpartum.

\title{
How to reference
}

In order to correctly reference this scholarly work, feel free to copy and paste the following:

Mohammed Helmy Faris Shalayel, Mohammed Chyad Al-Noaemi and Salah A.M. Ahmed (2011). Insulin Resistance in the Third Trimester of Pregnancy Suffering from Gestational Diabetes Mellitus or Impaired Glucose Tolerance, Gestational Diabetes, Prof. Miroslav Radenkovic (Ed.), ISBN: 978-953-307-581-5, InTech, Available from: http://www.intechopen.com/books/gestational-diabetes/insulin-resistance-in-the-third-trimesterof-pregnancy-suffering-from-gestational-diabetes-mellitus-

\section{INTECH}

open science | open minds

\section{InTech Europe}

University Campus STeP Ri

Slavka Krautzeka 83/A

51000 Rijeka, Croatia

Phone: +385 (51) 770447

Fax: +385 (51) 686166

www.intechopen.com

\section{InTech China}

Unit 405, Office Block, Hotel Equatorial Shanghai

No.65, Yan An Road (West), Shanghai, 200040, China

中国上海市延安西路65号上海国际贵都大饭店办公楼 405 单元

Phone: +86-21-62489820

Fax: $+86-21-62489821$ 
(C) 2011 The Author(s). Licensee IntechOpen. This is an open access article distributed under the terms of the Creative Commons Attribution 3.0 License, which permits unrestricted use, distribution, and reproduction in any medium, provided the original work is properly cited. 